\title{
Gel for Injection Dosage Form
}

National Cancer Institute

\section{Source}

National Cancer Institute. Gelfor Injection Dosage Form. NCI Thesaurus. Code C149537.

Sterile single-dose preparation consisting of a hydrophilic gel intended for injection into a specific tissue or organ. 